\title{
Nanofluids Application in the Drilling Process
}

Veikko Shalimba ${ }^{1}$, Bruno Sopko ${ }^{2}$

${ }^{1}$ Faculty of Mechanical Engineering, J. E. Purkyne University in Usti nad Labem. Pasteurova 3334/7, 40001 Usti nad Labem. Czech Republic. E-mail: veikko12@yahoo.com

${ }^{2}$ Institute of Material and Applied Physics, Czech Technical University in Prague, Horská 3a/22, 12800 Praha 2, Czech Republic. E-mail: Bruno.Sopko@fs.cvut.cz

\begin{abstract}
A high performance of heat transfer fluid has a great influence on the size, weight and cost of heat transfer systems, therefore a high-performance heat transfer fluid is very important in many industries. Over the last decades nanofluids have been developed. According to many researchers and publications on nanofluids its evident that nanofluids are found to exhibit enhance thermal conductivity. The aim of this experiment was to investigate the change of workpiece temperature during drilling using Jatropha oil with nanoparticle and water with iron nanoparticle as lubricating and cooling fluids. These experiments were carried out with samples of nanofluid with different volume ratio. Samples $J N 1, J N 5$ and $J N 10$ of iron nanoparticles in the base Jatropha oil with iron volume fraction $1 \%, 5 \%$ and $10 \%$ respectively. Samples $W N 1, W N 5$ and $W N 10$ of iron nanoparticles in the base water with iron volume fraction $1 \%, 5 \%$ and $10 \%$ respectively. The work arises from the projects which were realized at University J. E. Purkyně, Faculty of Mechanical Engineering, in cooperation with Namibia University of Science and technology, department of Mechanical Engineering.
\end{abstract}

Keywords: Jatropha oil, nanofluids, nanoparticles, temperature, drilling

\section{Introdution}

Cooling is a technical challenge facing many high technology industries today due to the rising demands of modern technology. Conventional heat transfer fluids have low thermal conductivity that limits their applications in high technology industries, therefore, there is an urgent need for new and innovative heat transfer fluids with improved performance. Many ideas have been implemented and many research activities have been carried out attempting to improve the thermal properties of heat transfer fluids.

The thermal conductivity of heat transfer fluids can be enhanced by the use of metallic or non-metallic nanoparticles in the base fluid which have been termed nanofluids [1], [5] [6]. This concept has attracted the attention of many researches worldwide into research on nanofluids due to their exciting thermal properties and their wide applications in numerous fields such as microelectronics, transportation, manufacturing, medicine, mining, energy, to name just a few.

A nanofluid is a fluid containing nanometer-size particles. The nanoparticles used in base fluid are normally made from metals, oxides, carbides or carbon nanotubes [2], [4]. Common conventional base fluids are water, ethylene glycol or oil. The key question still lingers concerning the best nanoparticle and base fluid pairing. According to many publications, nanofluid is considered to be the next-generation heat transfer fluid as it possesses enhance thermal properties such as thermal conductivity, thermal diffusivity and convective heat transfer coefficients compare to those of conventional fluid like water or oil [2], [3].

In this study, application of Jatropha oil with iron nanoparticles in drilling process was investigated and compared to that of water with iron nanoparticle nanofluids with similar volume concentration of nanoparticles. Drilling is a cutting process that uses a drill bit to cut a hole of circular cross-section in solid materials. Both rotating force and a downward pushing force are needed for drilling. However, drill bits generate a lot of heat energy in the process of metal cutting. Excessive heat generation during drilling process causes dull and reduces drill bits effective life span. Cutting fluid is sometimes used to cool down the tool and the workpiece. Besides cooling, cutting fluids also aid the cutting process by minimizing the cutting forces thus saving energy and by lubricating the interface contact between the tool's cutting edge and the workpiece. By preventing friction at this interface, some of the heat generation is prevented. This lubrication also helps to improve surface finish and preventing the chips from being welded onto the tool.

Most of metalworking and machining processes can benefit from the use of cutting fluid, depending on the workpiece material. One of the properties that are sought after in a good cutting fluid is the ability to keep the workpiece at a stable temperature. The aim of this experimental investigation is to determine the change of workpiece temperature during drilling using Jatropha oil with nanoparticle and water with iron nanoparticle as lubricating and cooling fluids.

\section{Samples Preparation and Characterizations}

In this experiment, nanofluids samples were prepared employing the two-step technique whereby, nanoparticles used are produced as dry powder. Afterwards, the powder at nanoscale size was dispersed into the base fluids. According to nanofluids researchers, one of the major problems encountered in the preparation of nanofluids is the formation of clusters of particles, which lead to poor dispersion therefore, high shear mixer was used in order to break up agglomerate and give more uniform dispersions [5]. However, no dispersant or surfactants were used to stabilize the nanofluid samples.

Six nanofluid samples with different volume ratio 
were selected as shown in Table 1. Samples $J N 1, J N 5$ and $J N 10$ of iron nanoparticles in the base Jatropha oil with different volume fraction $1 \%, 5 \%$ and $10 \%$ respectively. Samples $W N 1, W N 5$ and $W N 10$ of iron nanoparticles in the base water with different volume fraction $1 \%, 5 \%$ and $10 \%$ respectively. Sample $N W 1, N W 5$ and $N W 10$ are selected mainly for comparison purpose. Moreover, another two samples without iron nanoparticles have been selected for comparison purpose, i.e. oil-water emulsion and undiluted Jatropha oil, E100 and JN100 respectively. Oilwater emulsion used in this work was purchased in the Czech Republic.

Tab. 1 Sample characterization

\begin{tabular}{|c|c|c|}
\hline Sample & $\begin{array}{c}\text { Fluid volumetric } \\
\text { fraction [\%] }\end{array}$ & $\begin{array}{c}\text { Nanoparticles volume- } \\
\text { tric fraction [\%] }\end{array}$ \\
\hline E100 & 100 & - \\
\hline JN100 & 100 & - \\
\hline JN1 & 99 & 1 \\
\hline JN5 & 95 & 5 \\
\hline JN10 & 90 & 10 \\
\hline WN1 & 99 & 1 \\
\hline WN5 & 95 & 5 \\
\hline WN10 & 90 & 10 \\
\hline
\end{tabular}

The blend ratios were selected according to the ratio used in pervious researches and iron nanoparticles were selected due to the easy of suspension and availability in the market. Jatropha oil is a new material that is being researched for new applications. Water with iron nanoparticles samples were chosen because in general water is the heat transfer medium for all heat exchangers, because of its availability and good thermo-physical properties.

Iron nanoparticles with diameter of $25 \mathrm{~nm}$ and spherical shape were supplied by Nano Iron, s.r.o, Czech Republic. Jatropha oil used in this work is produced by the department of mechanical engineering at the University of Applied Science and Technology in Namibia. Samples of nanoparticles in the base Jatropha oil as well as in the base water were prepared at the laboratory of Nano Iron s.r.o. According to safety regulation EC.: 19017/2006, nanofluid samples used in this experiment were classified as not dangerous materials under the act on chemical substances and preparations. Nanofluids samples were stored in a cool place with temperature between $1-5^{\circ} \mathrm{C}$, in order to avoid excess pressure built-up in sample bottles. Nanofluid samples were kept in $500 \mathrm{ml}$ tightly sealed plastic bottles.

Jatropha oil was selected as the primary base fluid, in order to research potential applications of this oil, which is produced in large amount in Southern African Development Community (SADC) member states including Namibia. Water was selected as base fluid for comparison purposes since water is widely used in heat transfer application. However, water used as base fluid in these experiments was distilled in order to avoid the presence of ions which might have an impact on the thermo-physical properties and reduce the lifespan of the samples. Iron nanoparticles were employed as dispersed phase since they are easily produced as nanoparticles and their availability in the market. In addition, iron nanoparticles were used, due to their high thermal conductivity

\section{Experimental Method}

The experimental investigations were conducted on a vertical drilling machine installed at the Research Park, Department of Materials Science, Faculty of Mechanical Engineering, University J.E. Purkyně, using $5 \mathrm{~mm}$ diameter, High Speed Steel (HSS) drill bits. Steel ČSN 11523 (correspond to DIN St 52-3) was selected as workpiece material. Workpiece materials were cut into small workpieces of $30 \mathrm{~mm} \times 40 \mathrm{~mm} \times 10 \mathrm{~mm}$ as shown in Figure 1 . A calorimeter is used to minimize heat losses during the drilling operation. A modular design of a calorimeter with a fluid sample cup, workpiece fixing devices, body cover and top cover is newly developed. A liquid cup has a maximum volume of $80 \mathrm{ml}$ and during the experiment it was filled about $60 \mathrm{ml}$ of the fluid samples. The body cover and top cover are made out of expanded polystyrene material. The design allows smooth handling and clamping of the calorimeter on the drilling machine during experiments.

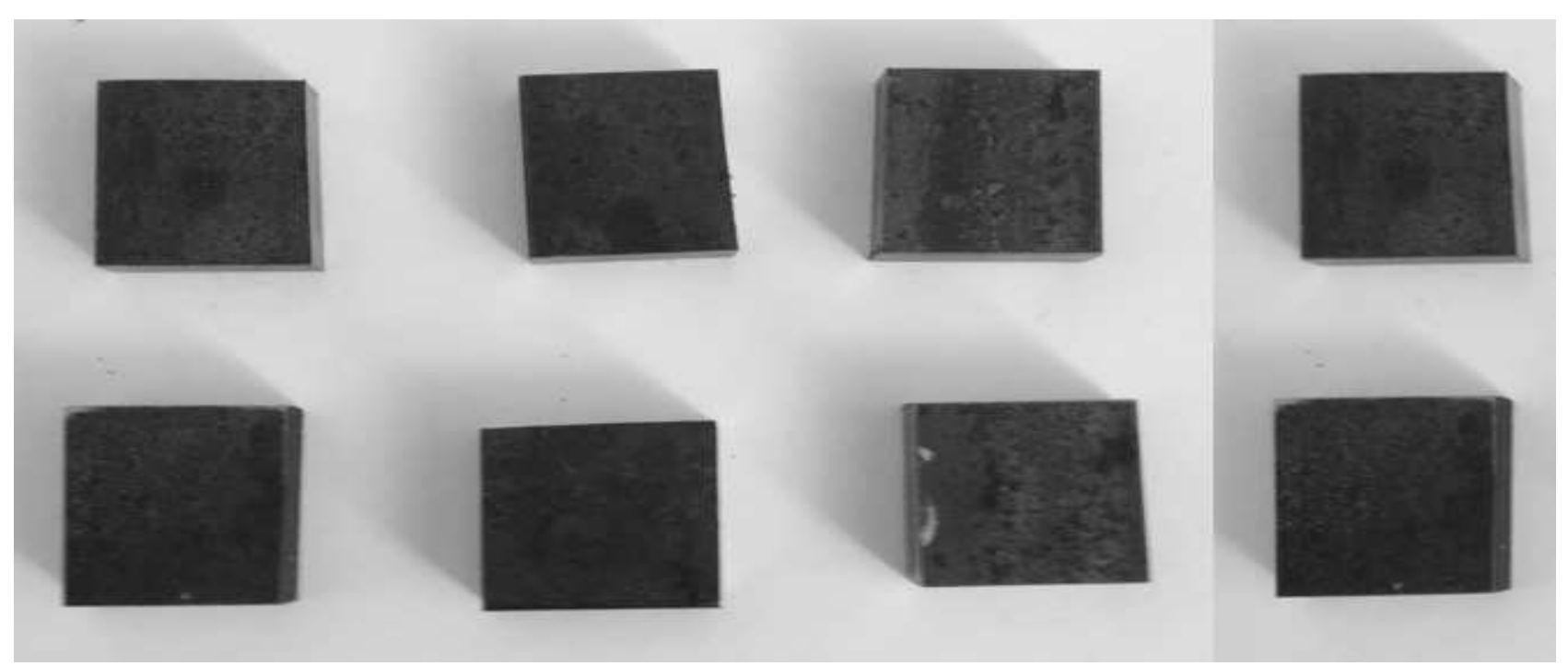

Fig. 1 Workpieces 

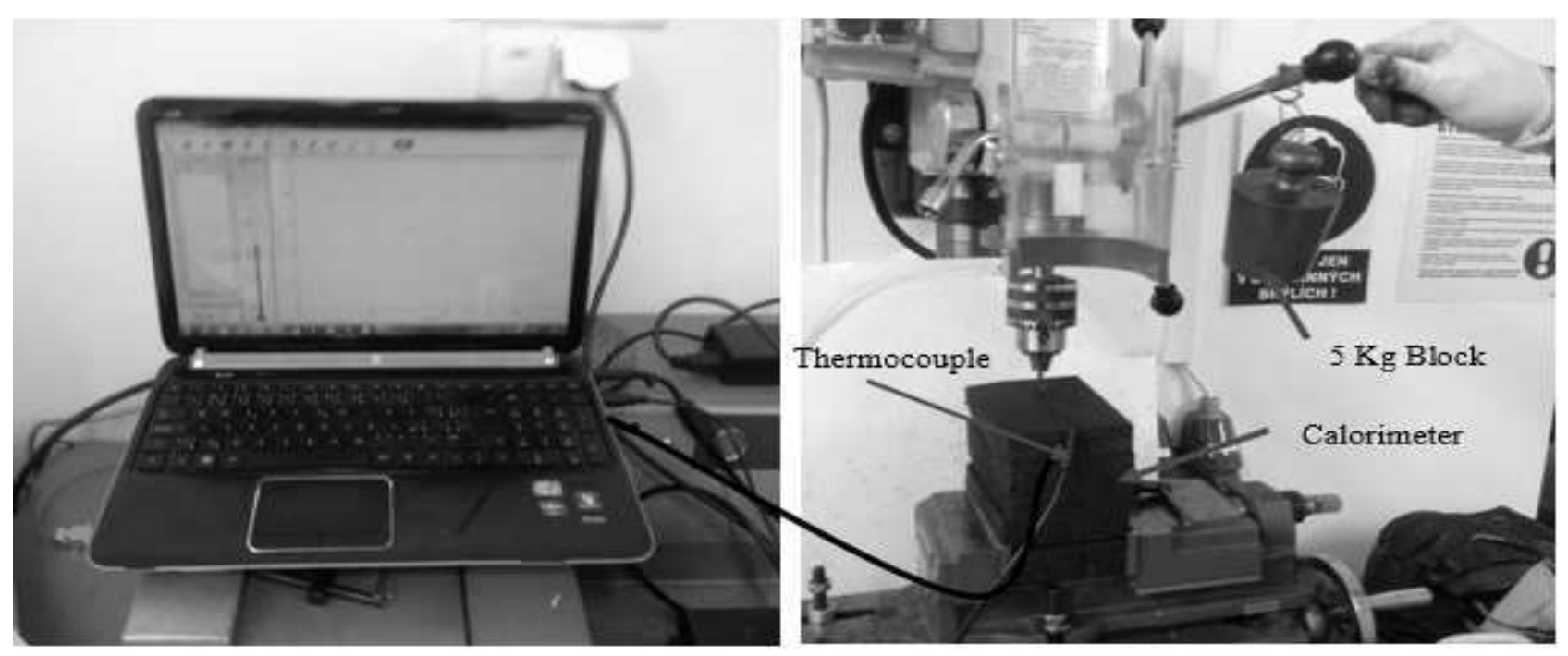

Fig. 2 Experimental setup for measurement of temperature in drilling process

The temperature during drilling process was measured by embedded thermocouple placed at location of $2 \mathrm{~mm}$ on the surface of a workpiece from the drilling point to quantify the temperature distribution in specimens submerged in the fluid samples $E 100, J 100, J N 1, J N 5, J N 10$, $W N 1, W N 5$ and $W N 10$. Symbols $E, J, J N$ and $W N$ stand for Emulse, Jatropha, Jatropha Nanoparticles and Water Nanoparticles, respectively.

Each experiment uses a new drill bit and workpiece. Spindle speed was set constant at $800 \mathrm{rpm}$ for all drilling experimental tests. To guarantee the initial condition of each test and feed rate, a weight of $5 \mathrm{~kg}$ was mounted on the drill feed handle, in order to have same feed rate for all drilling experimental tests using a manual feed rate drilling machine. The depth of cut was $10 \mathrm{~mm}$.

The experimental setup is shown in Figure 2. Temperature was measured before and after the experiments by thermocouple and change in temperature was obtained. All drilling experimental test were taken at room temperature around $23{ }^{\circ} \mathrm{C}$. Experimental tests were repeated 7 times and the average change in temperature was calculated.

\section{Results and Discussions}

The Experimental results of drilling tests for all measurement samples are depicted in Tabels 2-9 and Figures $3-11$.

Tab. 2 Change in temperature vs. time E100

\begin{tabular}{|l|c|c|c|c|c|c|c|c|c|}
\hline Time [s] & 0 & 10 & 20 & 30 & 40 & 50 & 60 & 70 & 80 \\
\hline Average temperature $\left[{ }^{\circ} \mathbf{C}\right]$ & 28.08 & 25.41 & 28.35 & 30.18 & 31.41 & 32.26 & 33.37 & 34.18 & 32.87 \\
\hline Standard deviation $\left[{ }^{\circ} \mathbf{C}\right]$ & 0 & 0.070 & 0.089 & 0.074 & 0.086 & 0.087 & 0.086 & 0.046 & 0.073 \\
\hline
\end{tabular}

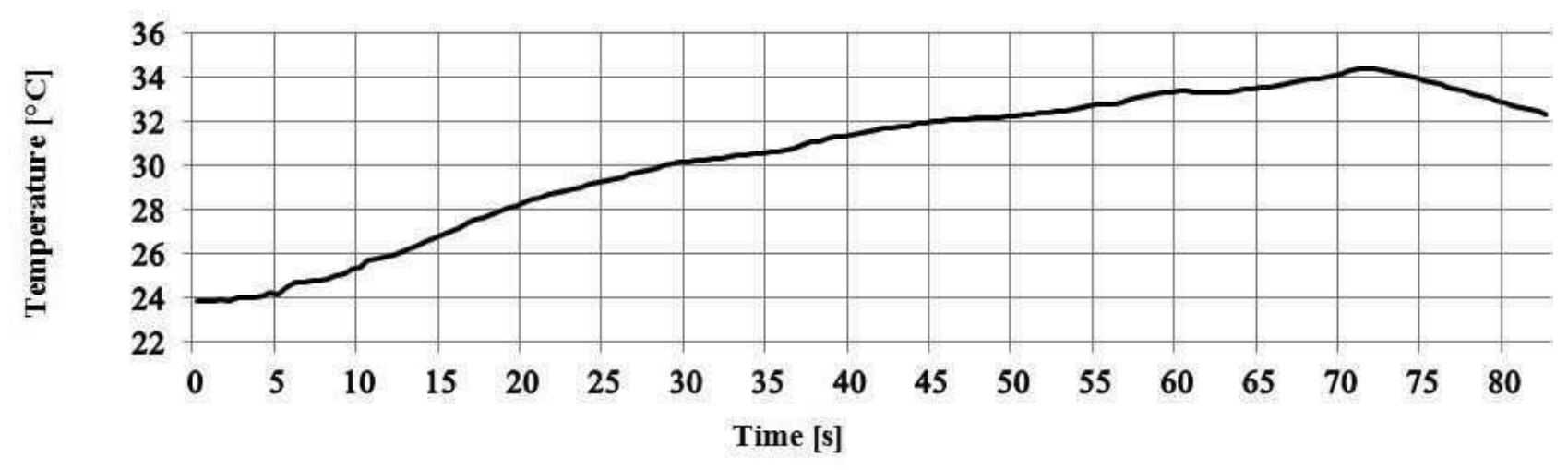

Fig. 3 Change in temperature vs. time - E100

Tab. 3 Change in temperature vs. time J100

\begin{tabular}{|l|c|c|c|c|c|c|c|c|c|c|}
\hline Time [s] & 0 & 10 & 20 & 30 & 40 & 50 & 60 & 70 & 80 & 90 \\
\hline Average temperature $\left[{ }^{\circ} \mathbf{C}\right]$ & 24.62 & 24.06 & 25.15 & 26.97 & 28.88 & 30.57 & 31.81 & 33.60 & 35.60 & 35.94 \\
\hline Standard deviation $\left[{ }^{\circ} \mathbf{C}\right]$ & 0 & 0.038 & 0.002 & 0.007 & 0.020 & 0.031 & 0.040 & 0.007 & 0.022 & 0.065 \\
\hline
\end{tabular}




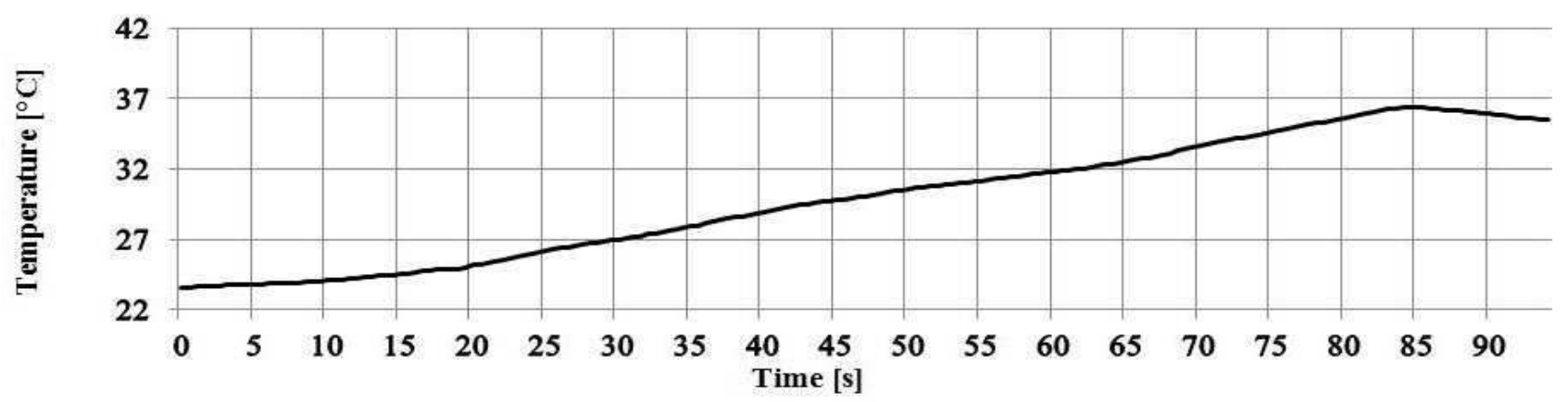

Fig. 4 Change in temperature vs. time - J100

Tab. 4 Change in temperature vs. time JN1

\begin{tabular}{|l|c|c|c|c|c|c|c|c|c|}
\hline Time [s] & 0 & 10 & 20 & 30 & 40 & 50 & 60 & 70 & 80 \\
\hline Average temperature $\left[{ }^{\circ} \mathbf{C}\right]$ & 23.60 & 24.07 & 25.00 & 26.56 & 28.49 & 30.48 & 31.81 & 33.10 & 32.87 \\
\hline Standard deviation $\left[{ }^{\circ} \mathbf{C}\right]$ & 0 & 0.037 & 0.006 & 0.059 & 0.063 & 0.041 & 0.040 & 0.048 & 0.008 \\
\hline
\end{tabular}

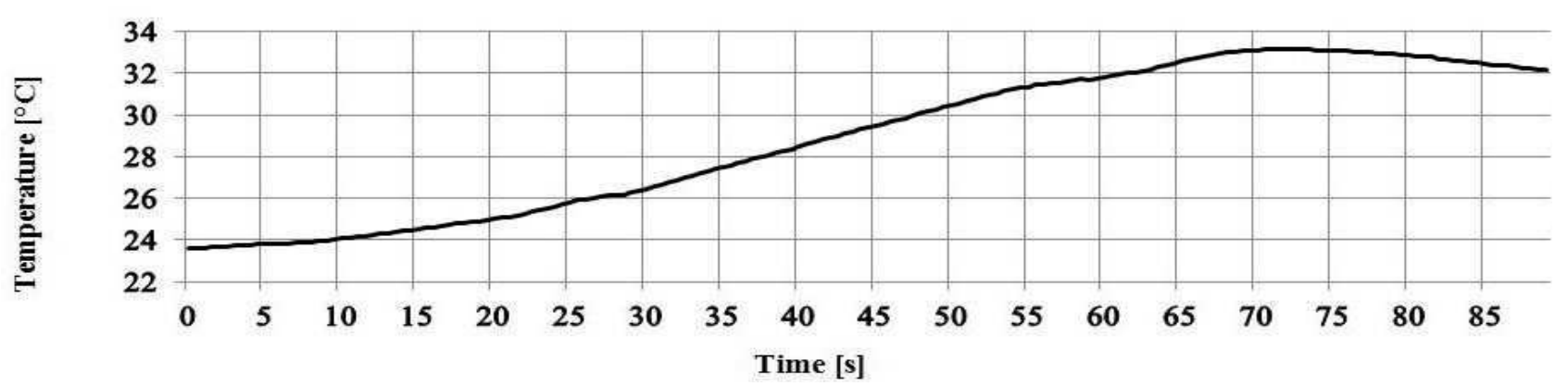

Fig. 5 Change in temperature vs. time - JN1

Tab. 5 Change in temperature vs. time JN5

\begin{tabular}{|l|c|c|c|c|c|c|}
\hline Time [s] & 0 & 10 & 20 & 30 & 40 & 50 \\
\hline Average temperature $\left[{ }^{\circ} \mathbf{C}\right]$ & 23.67 & 24.94 & 28.46 & 32.45 & 33.55 & 33.28 \\
\hline Standard deviation $\left[{ }^{\circ} \mathbf{C}\right]$ & 0 & 0.050 & 0.069 & 0.064 & 0.078 & 0.088 \\
\hline
\end{tabular}

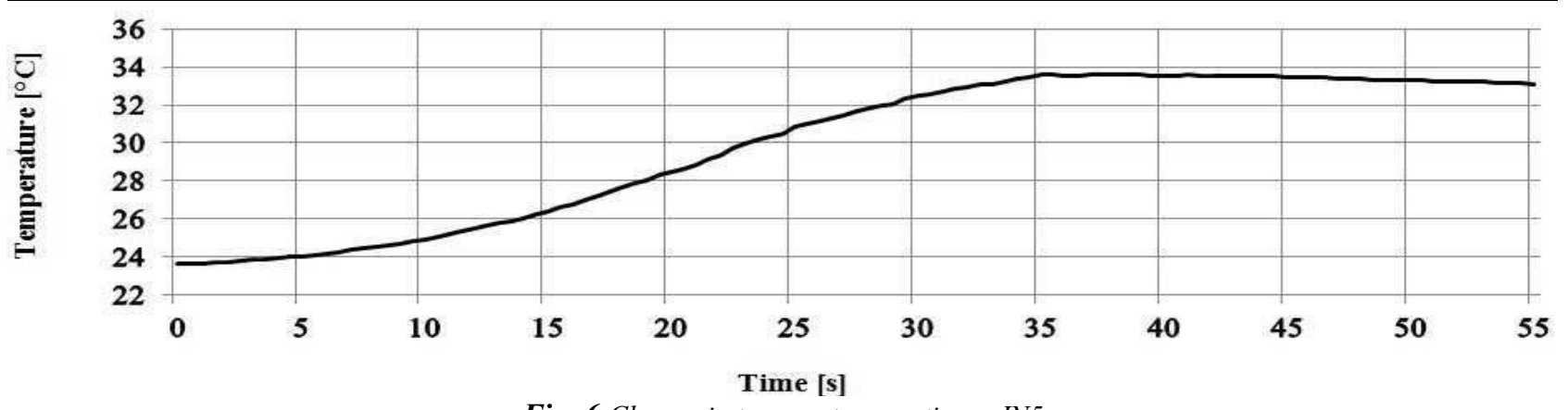

Fig. 6 Change in temperature vs. time - JN5

Tab. 6 Change in temperature vs. time JN10

\begin{tabular}{|l|c|c|c|c|c|}
\hline Time $[\mathbf{s}]$ & 0 & 10 & 20 & 30 & 40 \\
\hline Average temperature. $\left[{ }^{\circ} \mathbf{C}\right]$ & 23.64 & 24.57 & 28.23 & 33.36 & 32.88 \\
\hline Standard deviation $\left[{ }^{\circ} \mathbf{C}\right]$ & 0 & 0.023 & 0.031 & 0.042 & 0.012 \\
\hline
\end{tabular}

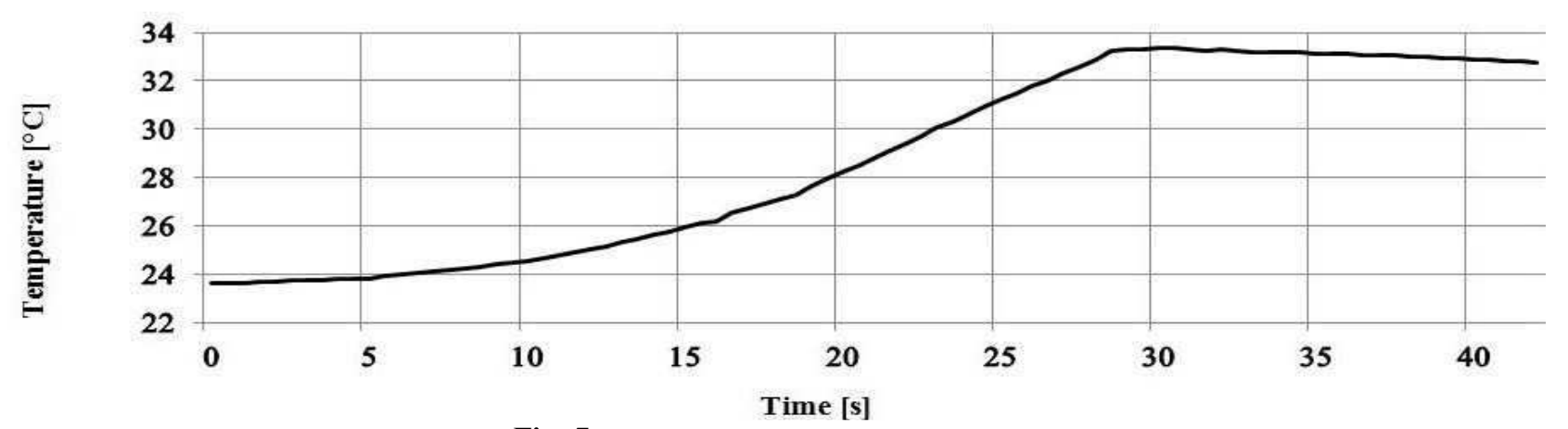

Fig. 7 Change in temperature vs. time - JN10 
Tab. 7 Change in temperature vs. time WN1

\begin{tabular}{|l|c|c|c|c|c|c|c|c|c|c|c|}
\hline Time $[\mathbf{s}]$ & 0 & 10 & 20 & 30 & 40 & 50 & 60 & 70 & 80 & 90 & 100 \\
\hline Av. temp. $\left[{ }^{\mathbf{}} \mathbf{C}\right]$ & 23.58 & 24.78 & 26.75 & 29.02 & 31.59 & 33.52 & 34.47 & 35.32 & 36.73 & 37.73 & 37.82 \\
\hline Standard d. $\left[{ }^{\circ} \mathbf{C}\right]$ & 0 & 0.047 & 0.410 & 0.040 & 0.500 & 0.044 & 0.049 & 0.430 & 0.049 & 0.049 & 0.053 \\
\hline
\end{tabular}

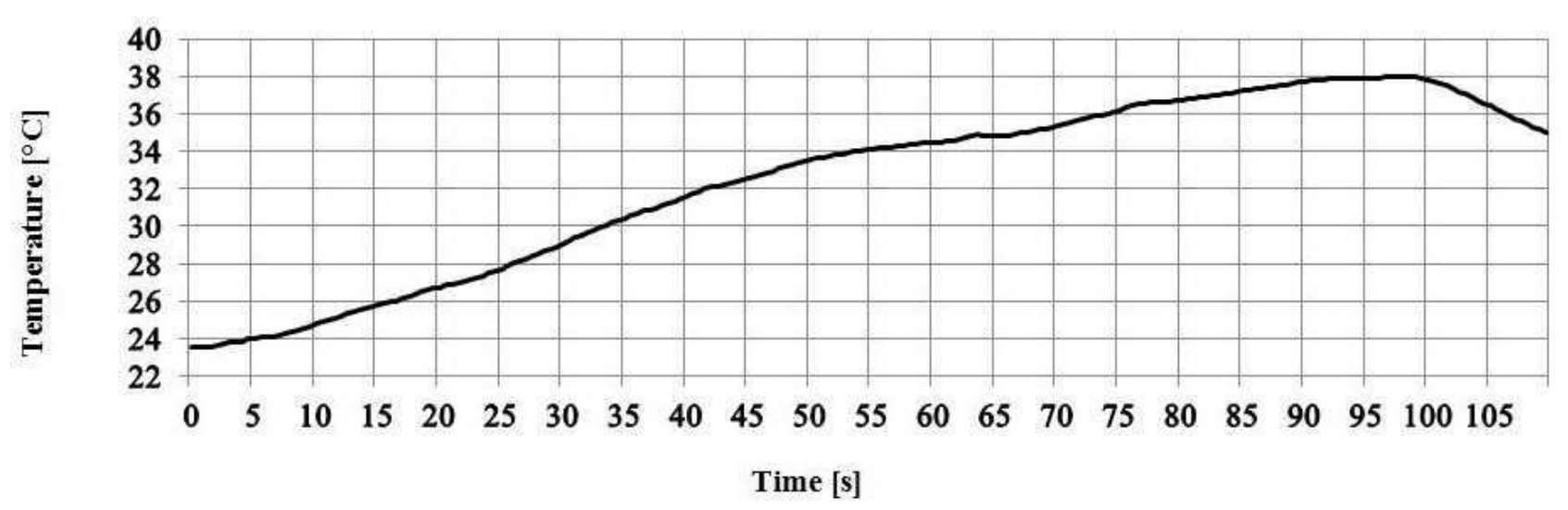

Fig. 8 Change in temperature vs. time - WN1

Tab. 8 Change in temperature vs. time WN5

\begin{tabular}{|l|c|c|c|c|c|c|c|c|c|c|c|}
\hline Time $[\mathbf{s}]$ & 0 & 10 & 20 & 30 & 40 & 50 & 60 & 70 & 80 & 90 & 100 \\
\hline Av. temp. $\left[{ }^{\circ} \mathbf{C}\right]$ & 23.60 & 29.34 & 29.93 & 30.93 & 32.05 & 33.51 & 34.68 & 36.15 & 37.83 & 39.22 & 39.25 \\
\hline Standard d. $\left[{ }^{\circ} \mathbf{C}\right]$ & 0 & 0.059 & 0.059 & 0.061 & 0.068 & 0.069 & 0.068 & 0.084 & 0.074 & 0.071 & 0.057 \\
\hline
\end{tabular}



Fig. 9 Change in temperature vs. time - WN5

Tab. 9 Change in temperature vs. time WN10

\begin{tabular}{|l|c|c|c|c|c|c|c|c|c|c|c|}
\hline Time $[\mathbf{s}]$ & 0 & 10 & 20 & 30 & 40 & 50 & 60 & 70 & 80 & 90 & 100 \\
\hline Av. temp. $\left[{ }^{\circ} \mathbf{C}\right]$ & 23.55 & 25.44 & 28.33 & 31.61 & 33.94 & 36.26 & 38.00 & 40.21 & 41.69 & 42.20 & 40.75 \\
\hline Standard d. $\left[{ }^{\circ} \mathbf{C}\right]$ & 0 & 0.056 & 0.053 & 0.043 & 0.046 & 0.046 & 0.058 & 0.065 & 0.065 & 0.047 & 0.055 \\
\hline
\end{tabular}

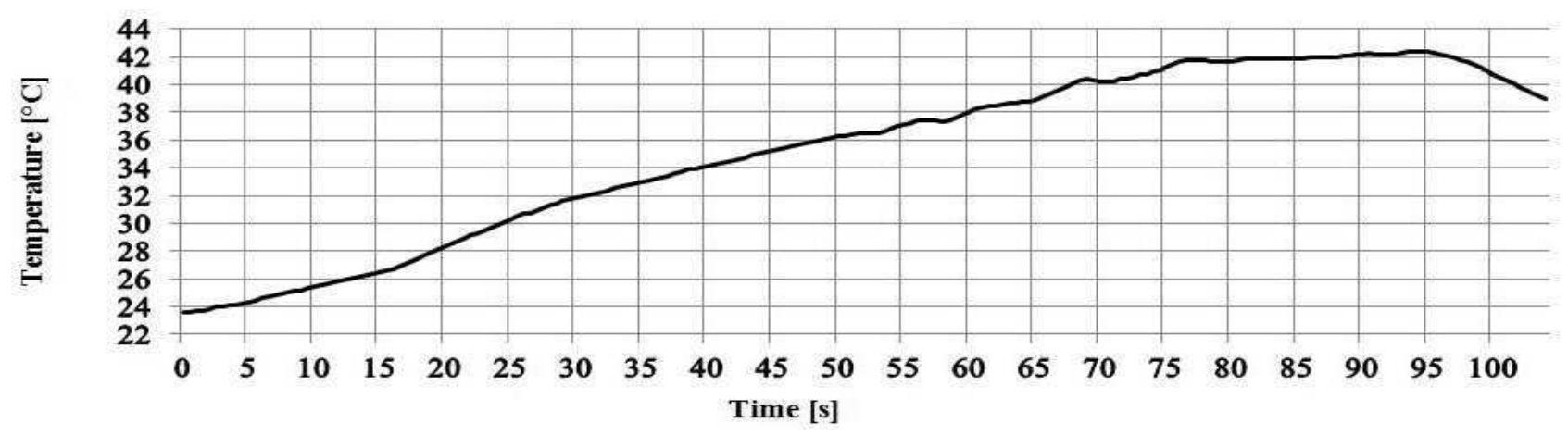

Fig. 10 Change in temperature vs. time - WN10

Figures 3 - 11 show change in temperature during drilling in specimens submerged in fluid samples of E100, J100, JN1, JN5, JN10, WN1, WN5, WN10 as well as drilling in a dry specimen DS. The graphs present both the increase and decline in temperature during drilling and after the drilling was completed. Figure 4.9 compares results of samples E100, J100, JN1, JN5, JN10, WN1, WN5, WN10. 


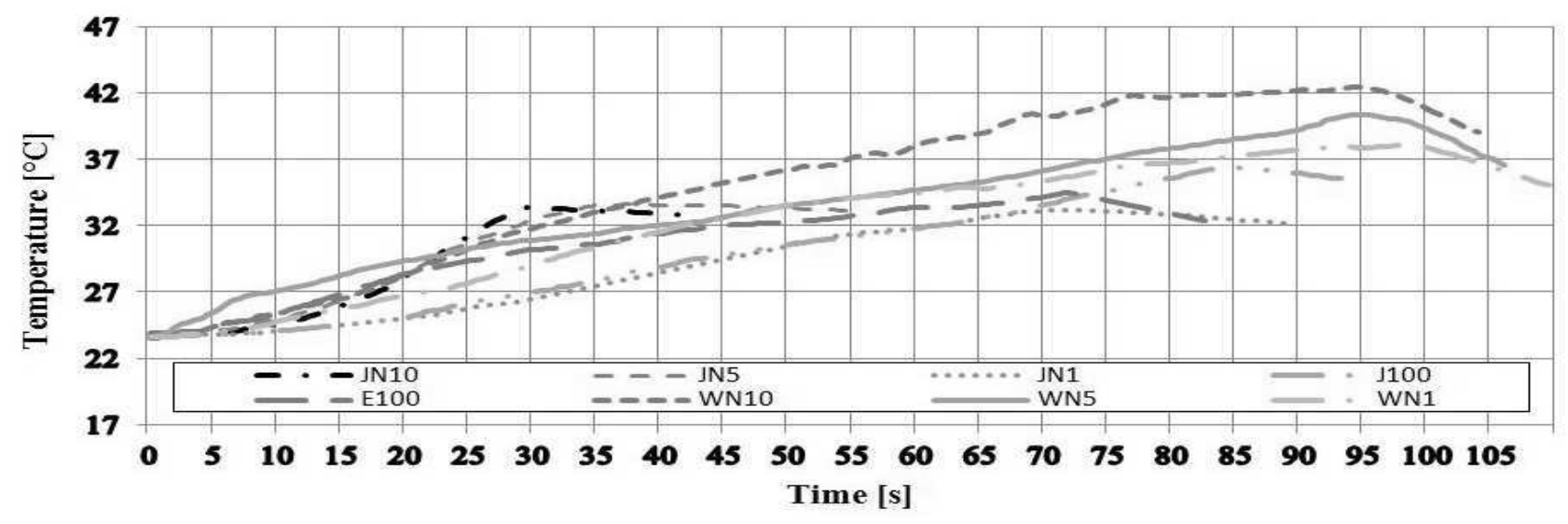

Fig. 11 Change in temperature vs. time - comparison

During the experimental tests temperature for all samples increased gradually, reaching a peak and dropping off slowly after the drilling depth of $10 \mathrm{~mm}$ was completed. Samples of Jatropha oil with iron nanoparticle $J N 1, J N 5$ and $J N 10$ had a shorter drilling time and lower peak temperature than sample of oil-water emulsion $E 100$, and samples of water with nanoparticles as shown in Figure 4.9; this indicate good lubrication, anti-wear properties and cooling performance. The shortest drilling time and lowest peak temperature was recorded on the experimental investigations of sample of $J N 10$ (with drilling time of 29 seconds and peak temperature of $33,3{ }^{\circ} \mathrm{C}$, as shown in Figure 4.5). Samples of water with iron nanoparticles were found with longer drilling times and higher peak temperatures than sample of oil-water emulsion E100. The longest drilling time and highest peak temperature was recorded on the experimental investigations of sample $W N 10$ (with drilling time of 95 seconds and peak temperature of $42,4{ }^{\circ} \mathrm{C}$, as shown in Figure 4.8). No wear was observed on the main cutting edges and dead center of HSS drill bits for all fluid samples.

\section{Conclusion}

The addition of nanoparticle concentration in Jatropha oil improves lubrication and cooling performance. During the drilling experimental tests temperature for all samples increased gradually, reaching a peak and then dropping off slowly after a drilling depth of $10 \mathrm{~mm}$ was reached. No wear was observed on the main cutting edges and dead center of HSS drill bits for all fluid samples.

\section{Acknowledgement}

The research work is supported by SGS UJEP Czech Republic.

\section{References}

[1] CHOI, S., EASTMAN, J. (1995). Enhancing Thermal Conductivity of Fluids with Nanoparticles. Proceedings of the ASME Mechanical Engineering Congress and Exposition. USA, pp. 99104. DOE W-31109-ENG-38.
[2] OZERINC, S. (2010). Heat transfer enhancement with nanofluids. Thesis, School of Natural and Applied Science: Middle East Technical University. $147 \mathrm{p}$.

[3] GAllegO, M., LUGO, L., LEGIDO, J, PINEIRO, M. (2011) Thermal Conductivity and Viscosity Measurements of Ethylene Glycol-Based $\mathrm{Al}_{2} \mathrm{O}_{3}$ Nanofluids. Nanoscale Research Letters. Springer Open, 11p. ISSN 1556-276X.

[4] MINKOWYCZ, W., SPARROW, E, W., ABRAHAM, J. (2013). Nanoparticle Heat transfer and Fluid Flow. New York, Tayloer \& Francis Group, Vol. 4, 335p. ISBN 13: 978-14398-61950 .

[5] DAS, K., CHOI, S., PRADDEP, T. (2007) Nanofluids Science and Technology. New Jersey, John Wiley \& Son, 407p. ISBN 978-0-470-07473-2.

[6] TIMOFEEVA, E. (2011) Nanofluids for Heat Transfer - Potential and Engineering Strategies. Energy Systems Division, Argonne National Laboratory, Illinois, pp. 435-450. ISBN 978-953307-584-6.

[7] RATHORE, M., KAPUNO, R.: Engineering Heat Transfer. (2011) Jones \& Bartlett Learning, 1096p. ISBN 13:978-0-7637-7752-4.

[8] POPOV, A., KRASNIKOV, I. (2018) Reducing Labour Intensity in the Development of New Universal Cutting Fluids for Machning. Manufacturing Technology, Vol, 18, No. 1, pp. 99-105. ISSN 1213-2489.

[9] DAŇA, M., ZATEK, M., SCHORNÍK, V. (2017) Effect of Cutting Edge Geometry on Cutting Forces when Drilling Inconel 718. Manufacturing Technology, Vol, 17, No. 1, pp. 24-29. ISSN 12132489.

[10] NOVOTNÝ, J., LYSOŇKOVÁ, I., MICHNA, Š., NÁPRSTKOVÁ, N. (2017) Research of Application Possibilities of Selected Mechanical Alloyed Metal Powders. Manufacturing Technology, Vol, 17, No. 5, pp. 811-815. ISSN 1213-2489. 